\title{
1789-1799 : combats de femmes. La Révolution exclut les citoyennes,
}

\section{Raymonde Monnier}

\section{Q OpenEdition \\ 1 Journals}

Édition électronique

URL : https://journals.openedition.org/ahrf/1863

DOI : 10.4000/ahrf.1863

ISSN : 1952-403X

Éditeur :

Armand Colin, Société des études robespierristes

Édition imprimée

Date de publication : 1 décembre 2004

Pagination : 168-170

ISSN : 0003-4436

Référence électronique

Raymonde Monnier, «1789-1799: combats de femmes. La Révolution exclut les citoyennes, »,

Annales historiques de la Révolution française [En ligne], 338 | octobre-décembre 2004, mis en ligne le 22 mars 2006, consulté le 22 avril 2022. URL : http://journals.openedition.org/ahrf/1863 ; DOI : https:// doi.org/10.4000/ahrf.1863

Ce document a été généré automatiquement le 22 avril 2022.

Tous droits réservés 


\title{
1789-1799 : combats de femmes. La Révolution exclut les citoyennes,
}

\author{
Raymonde Monnier
}

\section{RÉFÉRENCE}

1789-1799 : combats de femmes. La Révolution exclut les citoyennes, dirigé par Evelyne MorinRotureau, Paris, Editions Autrement, Collection Mémoires n 96, 2003, 248 p., ISBN :

2-7467-0397-1, $19 €$.

1 Un cycle de conférences sur la Révolution française, organisé au Mans par la délégation départementale aux droits de la femme de la Sarthe en 2001-2002, est à l'origine de ce volume. On peut s'interroger avec Elizabeth G. Sledziewski sur le sens de l'intérêt nouveau porté par l'historiographie à la misogynie intrinsèque des révolutionnaires; le jugement négatif porté sur leur politique envers les femmes serait-il devenu un motif acceptable pour les évincer du panthéon républicain ? On peut certes juger sévèrement une révolution qui en décorant les femmes du titre de citoyennes leur refuse le droit de cité. Mais un Talleyrand aurait-il pu compter sur le consensus des membres de l'Assemblée pour exclure les femmes, au nom de la décence des mœurs et de la paix des familles, s'il n'avait pu compter que sur la force des préjugés? Les révolutionnaires, qui par ailleurs n'ont pas manqué d'audace, n'ont-ils pas été si peu enclins à les combattre en ce domaine parce qu'ils prenaient pour guides l'autorité morale et les théories des philosophes et des encyclopédistes. Seule avancée notable, la législation sur le divorce s'appuie sur la laïcisation de la société, les idées des juristes et des philosophes des Lumières. En ne considérant "plus le mariage que comme un contrat civil», la Constituante ouvre la voie à la loi du 20 septembre1792, dont les effets, comme le montre l'article de synthèse de Dominique Dessertine, introduit à une période de transition, dont les femmes ont largement profité, surtout dans les grandes villes, et où le mariage peut être aussi pour les nouvelles générations attente de bonheur. 
2 Mais comment penser la différence dans l'universalisme des Lumières ? abstraitement égalitariste et concrètement discriminatoire, la doctrine exige la soumission aux décrets de la nature, une nature qui ne poursuit aucune fin métaphysique, mais se trouve être utilement convertible en finalité sociale. Jaucourt dans l'Encyclopédie, s'en remet à l'Histoire pour vérifier le bien fondé d'une subordination conventionnelle dans la vie domestique. Chez Voltaire, sans remettre en cause les bases de la société, la différenciation des rôles suit la forme d'une véritable doctrine fondée sur l'axiome de l'anthropologie moderne: «Le physique gouverne toujours le moral». La nouvelle société est autorisée à se passer du Ciel « sans renoncer à l'ordre domestique, base de l'ordre public ». À suivre l'analyse d'Yvonne Knibiehler sur le discours médical, de l'Encyclopédie au Dictionnaire des sciences médicales (1812-1822), il semble que l'infériorité de la «nature féminine » s'accuse sur le demi-siècle qui les sépare. Les intuitions de la recherche expérimentale butent sur une pensée scientifique surdéterminée par les facteurs socio-culturels. La faiblesse de la constitution féminine scientifiquement posée et les rapports entre physique et moral contribuent à justifier le rôle assigné aux femmes dans la société. Au début du 19e siècle, entre nature et spiritualité, les femmes doivent savoir librement se soumettre à leur destin, et surtout hors de l'histoire politique, apanage exclusif des hommes libres, rappelle Michèle Riot-Sarcey. Comme si les femmes étaient placées, au sein même de mutations sociales accélérées, dans un invariant féminin pensé comme immuable.

3 Pourtant les femmes avaient réussi à gagner une place reconnue dans la société de la fin de l'ancien régime, notamment à Paris dans le monde des arts et des lettres. On retiendra particulièrement pour la nouveauté et la qualité de ses analyses la contribution de Marie-Jo Bonnet sur les stratégies des femmes peintres à la fin du 18e siècle pour gagner leur identité d'artistes. C'est le cas d'Adélaïde Labille-Guiard et d'Elizabeth Vigée Le Brun, qui accèdent à la reconnaissance dans le monde jusque-là fermé des Académies par leur seul talent. Olivier Blanc replace à propos Olympe de Gouges, si maltraitée par l'historiographie révolutionnaire, non seulement dans le Paris mondain des salons, mais encore dans le milieu libéral des auteurs dramatiques engagés en faveur des droits de l'homme dans les années 1780, contre les abus de l'ancien régime. La fille naturelle du très conservateur Lefranc de Pompignan tenait son rôle d'auteur engagé, en traitant de sujets de société comme le divorce, les vœux perpétuels ou les enfants naturels, et faisait jouer ses pièces dans son propre théâtre. Elle s'était fait connaître par une pièce contre l'esclavage Zamore et Mirza, qui fut acceptée moyennant retouches par les Comédiens français. Ses écrits lui valent l'honneur d'être retenue en 1808 par Grégoire - la seule femme française - sur la liste des "hommes courageux" qui plaidèrent alors la "cause des malheureux Noirs et Sang-mêlés ». Son combat en faveur de la liberté et du droit des femmes, contre le préjugé général, signa sa perte au plus fort des luttes révolutionnaires de l'été 1793 ; sa condamnation fut saluée dans la presse par des arguments moins politiques qu'assez odieusement sexistes.

4 Autre dossier repris dans ce volume, celui de la résistance des femmes à la révolution. L'attitude des religieuses face à la suppression des communautés fut-elle globalement opposée à la révolution? Le cas du diocèse de Poitiers, étudié par Gwénaël Murphy, montre que si le refus et la résistance sont effectives (moins de $10 \%$ prêtent les serments prescrits), d'autres se soumettent et s'adaptent, soit consentement soit résignation. Fait significatif, une bonne partie des plus jeunes se marient. À l'autre 
extrême, le refus s'affiche par l'émigration ou la résistance aux côtés de la Vendée. Quelle fut l'attitude des Vendéennes dans la guerre? À l'opposé de la thèse de l'hagiographie vendéenne qui minimise leur rôle tout en exaltant quelques héroïnes, elles ont été pour les auteurs républicains les actrices essentielles du soulèvement. Claude Petitfrère nuance ces interprétations contradictoires, car si un certain nombre jouent un rôle actif dans la guerre, beaucoup ne font que suivre l'armée, notamment après la défaite de Cholet, pour rester avec leurs hommes, sous la protection des armes. Elles subissent à part égale la violence de la répression et de la guerre civile.

De la Révolution à nos jours, le conservatisme social a dû changer d'arguments pour justifier l'exclusion du droit de cité et s'opposer à la mise en œuvre de l'égalité des droits. Cependant le destin posthume des "héroïnes" qui se sont distinguées de quelque manière, n'échappe pas aux stéréotypes, de la reine maléfique incarnant la quintessence de la féminité dévoyée, à l'égérie de la Gironde, Madame Roland, certes mieux traitée par l'historiographie, mais dont la fermeté même devant le mort aura pu être jugée en son temps comme un trait contre nature. Catherine Marand-Fouquet, qui présente cette galerie de femmes révolutionnaires, rappelle que le temps de la révolution fut un temps de guerre et que les femmes ont eu l'occasion d'exprimer aussi leur patriotisme, notamment en prenant leur mission éducative au sérieux. Christine Fauré évoque les gestes symboliques, tels le don et le serment civiques, par lesquels les femmes ont pu sous la révolution éprouver leur appartenance à la Cité et exprimer leur adhésion au régime. Elle suit au fil des Constitutions, de la Déclaration de 1789 à la Constitution de 1958 en passant par la Déclaration universelle des droits de l'homme de 1948 , le jeu de références à travers lequel la différence des sexes se trouve comme neutralisée. L'égalité des voies d'accès à la sphère politique demeure un horizon d'espérance ; l'universalisme abstrait peut-il encore servir d'argument à la République pour barrer les moyens nécessaires à sa mise en œuvre? On appréciera ces regards croisés sur le destin des femmes et la richesse des thèmes traités dans ce volume, qui reproduit la Déclaration des droits de la femmes et de la citoyenne d'Olympe de Gouges, et est complété par un index et une abondante bibliographie. 